\title{
Discussion
}

\section{Lynch Syndrome: An Updated Review}

\author{
Rishabh Sehgal, Kieran Sheahan, Patrick R. O’Connell, Ann M. Hanly, Sean T. Martin and \\ Desmond C. Winter*
}

Centre for Colorectal Disease, St. Vincent's University Hospital, Elm Park, Dublin 4, Ireland; E-Mails: rishsehgal@gmail.com (R.S.); K.Sheahan@st-vincents.ie (K.S.);

Ronan.OConnell@ucd.ie (R.O.C.); annhanly@rcsi.ie (A.M.H.); drseanmartin@gmail.com (S.T.M.)

* Author to whom correspondence should be addressed; E-Mail: des.winter@gmail.com; Tel.: +353-1-2614-010; Fax: +353-1-2614-096.

Received: 3 December 2013; in revised form: 30 April 2014 / Accepted: 9 May 2014 /

Published: 27 June 2014

\begin{abstract}
Lynch syndrome is one of the most common cancer susceptibility syndromes. Individuals with Lynch syndrome have a 50\%-70\% lifetime risk of colorectal cancer, $40 \%-60 \%$ risk of endometrial cancer, and increased risks of several other malignancies. It is caused by germline mutations in the DNA mismatch repair genes $M L H 1, M S H 2$, MSH6 or PMS2. In a subset of patients, Lynch syndrome is caused by $3^{\prime}$ end deletions of the EPCAM gene, which can lead to epigenetic silencing of the closely linked MSH2. Relying solely on age and family history based criteria inaccurately identifies eligibility for Lynch syndrome screening or testing in $25 \%-70 \%$ of cases. There has been a steady increase in Lynch syndrome tumor screening programs since 2000 and institutions are rapidly adopting a universal screening approach to identify the patients that would benefit from genetic counseling and germline testing. These include microsatellite instability testing and/or immunohistochemical testing to identify tumor mismatch repair deficiencies. However, universal screening is not standard across institutions. Furthermore, variation exists regarding the optimum method for tracking and disclosing results. In this review, we summarize traditional screening criteria for Lynch syndrome, and discuss universal screening methods. International guidelines are necessary to standardize Lynch syndrome high-risk clinics.
\end{abstract}

Keywords: Lynch syndrome; genetics; screening; history; CRC clinic 


\section{Introduction}

Approximately $2 \%-5 \%$ of all colorectal cancers (CRC) arise from a defined inherited cancer syndrome [1]. Lynch syndrome (formerly known as hereditary nonpolyposis colorectal cancer, HNPCC) and familial adenomatous polyposis (FAP) are autosomal dominant genetic disorders that comprise the majority of these. Other less common familial CRC syndromes include the hamartomatous syndromes, hyperplastic polyposis syndromes, the autosomal recessive MYH-associated polyposis syndrome, and familial juvenile polyposis. Although the global incidence of heritable CRC is relatively low when compared to their sporadic counterpart, early identification of such high-risk individuals and their families is important in order to commence timely screening and surveillance programs.

Lynch syndrome is caused by germline mutations in DNA mismatch repair (MMR) genes MLH1, MSH2, MSH6 and PMS2. Also genomic rearrangements within the epithelial cell adhesion molecule gene EPCAM can lead to silencing of the closely linked MSH2 gene in EPCAM-expressing tissues. CRCs in Lynch syndrome are characterized by an adenoma-carcinoma progression ratio of 1:1 (estimated adenoma-cancer transformation time 1-3 years), as compared to sporadic cases that have a ratio of 30:1 (estimated adenoma-cancer transformation time 8-17 years) [2]. If left untreated, the majority of polyps will become malignant as observed in approximately $70 \%$ of patients at age 70 and $80 \%$ of patients at 85 years. There is an increased incidence of metachronous and synchronous colon cancers with a second primary CRC developing in up to 30\% after 10 years and 50\% after 15 years [2]. Lynch syndrome predisposes to extracolonic malignancies involving the endometrium, stomach, ovaries, small bowel, hepatobiliary epithelium, uroepithelial epithelium and brain [1,2].

The aim of this manuscript is to review the history and genetics of Lynch syndrome and provide a discussion pertaining to the clinical and molecular diagnostics, universal tumor screening and changes in testing paradigms.

\section{History of Lynch Syndrome}

The history of Lynch syndrome dates back to 1895 when Aldred Scott Warthin worked as the Chairman of the Department of Pathology at the University of Michigan, School of Medicine in Ann Arbor. He astutely observed his German seamstress to be depressed over the thought that she too would eventually succumb to gastric, colonic, or uterine cancer similar to the other members of her family. Indeed, she did die of endometrial cancer at an early age. Warthin studied her family in detail and published this large pedigree of 10 affected family members in 1913 outlining many generations affected by colonic, gastric and uterine cancers [3,4]. He performed an audit of 3600 cancer cases diagnosed in his laboratory between 1895 and 1912 and observed that approximately 15\% of those had a positive family history of carcinoma. Warthin concluded that there was "some influence of heredity on cancer" [5]. An updated report on Family G was published in 1925. There was a higher familial preponderance for cancers of the gastrointestinal tract and uterus. Such cancers affected family members at a median age of 37.9 years and had a tendency for CRC to develop in the proximal colon. Warthin died in 1931 [5].

In 1966, Henry Lynch described two families from Nebraska (N) and Michigan (M) that had similar cancer patterns involving multi-generations that were akin to the original Family G. He studied the 
data from over 650 Family G members and later published his "Cancer Family 'G' Revisited" manuscript in 1971 [6] that solidified the evidence which characterized this syndromic disease as having an autosomal dominant inheritance pattern and an early age of onset (average age at onset $<45$ years) and involving adenocarcinomas of the colon, endometrium, and stomach [5]. Several other similar reports describing HNPCC were published in the mid-1980s and a number of clinical classification schemas were developed for research purposes [7-10].

In 1989, the International Collaborative Group on HNPCC (ICG-HNPCC) was established which developed a set of criteria known as the "Amsterdam criteria-I" for the diagnosis of HNPCC to facilitate identification of causative genes [11]. This was further broadened in 1999 to incorporate extracolonic tumours and was known as "Amsterdam criteria-II" [12]. With the identification of several mutations within the MMR genes (MLH1, MSH2, MSH6, and PMS2), the National Cancer Institute held an International Workshop on Lynch syndrome in Bethesda in November, 1997 [13]. They reported a standardized diagnostic panel of microsatellite markers and developed the Bethesda Guidelines for selecting patients' CRC for MSI analysis [13,14]. These guidelines were revised and published in 2004 to include family history and specific pathologic features of CRC such as signet ring cell features, Crohn's like reaction, mucinous features and location of the tumor in the right colon [15] (Table 1). These general guidelines have limitations as many Lynch syndrome families will not meet the Amsterdam Criteria or the Bethesda Guidelines. Conversely, despite meeting such criteria or guidelines, some families will not possess germline alterations in any DNA MMR genes. In 2008, Hampel et al. demonstrated the feasibility of large-scale immunohistochemistry (IHC) that could aid in directing genetic testing [1]. In 2009, the Jerusalem Workshop recommended routine MSI testing or immunohistochemistry for all CRCs diagnosed in patients below the age of 70 years [16]. These recommendations were incorporated into the Evaluation of Genomic Application in Practice and Prevention (EGAPP) evidence report [17].

Table 1. Breakdown of the Amsterdam Criteria I+II and Revised Bethesda Guidelines [11-15].

Amsterdam Criteria I

At least three relatives with histologically verified colorectal cancer:

1. One is a first-degree relative of the other two;

2. At least two successive generations affected;

3. At least one of the relatives with colorectal cancer diagnosed at $<50$ years of age;

4. Familial adenomatous polyposis (FAP) has been excluded.

\section{Amsterdam Criteria II}

At least three relatives with an hereditary nonpolyposis colorectal cancer (HNPCC)-associated cancer [colorectal cancer, endometrial, stomach, ovary, ureter/renal pelvis, brain, small bowel, hepatobiliary tract, and skin (sebaceous tumours)]:

1. One is a first-degree relative of the other two;

2. At least two successive generations affected;

3. At least one of the syndrome-associated cancers should be diagnosed at $<50$ years of age;

4. FAP should be excluded in any colorectal cancer cases;

5. Tumors should be verified whenever possible. 
Table 1. Cont.

Revised Bethesda Guidelines

Colorectal tumors from individuals should be tested for MSI in the following situations:

1. Colorectal cancer diagnosed in a patient who is $<50$ years of age.

2. Presence of synchronous or metachronous colorectal, or other HNPCC-associated tumors regardless of age.

3. Colorectal cancer with microsatellite instability-high (MSI-H) histology diagnosed in a patient who is $<60$ years of age.

4. Colorectal cancer diagnosed in one or more first-degree relatives with an HNPCC-related tumor, with one of the cancers being diagnosed under age 50 years.

5. Colorectal cancer diagnosed in two or more first- or second-degree relatives with HNPCC-related tumors, regardless of age.

\section{Genetics of Lynch Syndrome}

The majority of CRC develop sporadically from somatic alterations in colon epithelial cells; however, in up to $30 \%$ of cases, CRC develops in patients that have a strong family history. Patients with affected first-degree relatives have a 2-10 times increased risk of developing CRC and in the absence of a Lynch or polyposis syndrome probably harbor incompletely penetrant variants in a range of genes. Lynch syndrome patients have inherited at least one defective allele of a MMR gene. The normal function of the MMR proteins is to proofread the nucleotide sequence for potential base-base errors that occur during DNA synthesis. Microsatellites are short repetitive sequences that are distributed throughout the human genome. Defective MMR causes variations within the microsatellites, manifesting as a gain or loss in repeat length. This is described as microsatellite instability (MSI) [18-21]. Cancers that possess more than $40 \%$ microsatellite variations (i.e., positive for two or more of the five standard microsatellite markers routinely tested) are described as high frequency MSI (MSI-H). Interestingly, this phenotype is also observed in $15 \%$ of sporadic CRCs due to somatic methylation of the $M L H 1$ promoter region. Further genotyping for the BRAF somatic V600E mutation can be performed to confirm somatic occurrences of MSI. Mutations of the BRAF gene with methylation of MLH1 are typical of sporadic CRC and are almost never seen in Lynch syndrome [22-24]. Tumors that have no MSI are microsatellite stable (MSS) and those that possess less than $40 \%$ microsatellite variations (i.e., one out of the five standard markers showing microsatellite instability) are low frequency MSI (MSI-L), although the relevance of this group is uncertain and these tumours are not considered microsatellite unstable [22-24].

The majority of individuals with Lynch syndrome possess at least one pathogenic germline mutation of the MMR genes MLH1, MSH2, MSH6 or PMS2. MLH1 and MSH2 genes are by far the most commonly mutated in Lynch syndrome patients accounting for $\sim 70 \%$ of the mutations identified (32\% in $M L H 1$ and 38\% in MSH2) [25,26]. Individuals who carry mutations in the MSH2 gene have a preponderance for developing extracolonic cancer and a lower frequency of CRC when compared with MLH1 [27,28]. MSH6 mutations are commonly linked with gastrointestinal and endometrial cancer, and a later age of presentation [29,30]. MSH6 is also recognized as a frequent cause of atypical Lynch syndrome (i.e., not fulfilling the Amsterdam criteria) [29,30]. Senter et al. analysed 99 probands diagnosed with Lynch syndrome associated tumors showing isolated loss of PMS2 and demonstrated 
germline PMS2 mutation in $62 \%$ of probands [31]. Among families with monoallelic PMS2 mutations, $65.5 \%$ met revised Bethesda guidelines and the penetrance for monoallelic mutation carriers was lower than for the other MMR genes [31].

Recently, constitutional 3' deletions of EPCAM have been shown to cause Lynch syndrome through epigenetic silencing of $M S H 2$ in EPCAM-expressing tissues, resulting in tissue-specific MSH2 deficiency [32]. Kempers et al. performed a cohort study comparing 194 patients carrying the EPCAM deletion to 473 patients carrying a mutation in $M L H 1, M S H 2, M S H 6$, or a combined EPCAM-MSH2 deletion. Carriers of an EPCAM deletion had a $75 \%$ cumulative risk of colorectal cancer before the age of 70 years, which did not differ significantly from that of carriers of combined EPCAM-MSH2 deletion or mutations in MSH2, but was higher than noted for carriers of MSH6 mutation. Only those with deletions extending close to the $M S H 2$ promoter had an increased risk of endometrial cancer. Therefore, these results underscore the effect of mosaic MSH2 deficiency, leading to variable cancer risks, and could form the basis of an optimized protocol for the recognition and targeted prevention of cancer in EPCAM deletion carriers [33].

So far, genome wide association studies have identified approximately 20 gene variants associated with the development of sporadic CRC [34]. Wijnen et al. have identified the single nucleotide polymorphism rs16892766 (8q23.3) and rs3802842 (11q23.1) to be significantly associated with CRC risk in Lynch syndrome families [35]. For rs16892766, possession of the C-allele was associated with an elevated risk of CRC in a dose-dependent fashion, with homozygosity for CC being associated with a 2.16-fold increased risk. For rs3802842, the increased risk of CRC associated with the C-allele was only found among female carriers, while CRC risk was substantially higher among homozygous compared to the heterozygous carriers of the $\mathrm{C}$-allele. In an additive model of both variants, the risk was significantly associated with the number of risk alleles. The effects were stronger in female carriers than in male carriers. Such modifiers may aid in identifying high-risk individuals who require more intensive surveillance [35].

Interestingly, of all the families who meet the Amsterdam- 1 criteria, approximately $80 \%$ of families carry a hereditary abnormality in a MMR gene. In order to determine whether cancer risk in Amsterdam-1 families with no apparent deficiency in DNA MMR was different from cancer risk in Amsterdam-1 families with DNA MMR abnormalities, Lindor et al. identified 161 Amsterdam-1 pedigrees and compared families with and without MMR abnormalities [36]. Families who fulfilled the Amsterdam criteria-1 and did not possess a DNA MMR defect did not share the same cancer incidence as families with hereditary MMR deficiency. Relatives in such families carried a modest risk of developing $\mathrm{CRC}$ at an older age without extracolonic malignancies when compared to those who have an identifiable mismatch repair gene defects. Therefore, in order to distinguish these cohorts apart, the designation of "familial CRC type X" was suggested for this type of familial aggregation of CRC [36].

The Human Variome Project has recently established a pilot project in conjunction with the International Society for Gastrointestinal Hereditary Tumours (InSiGHT) in order to interrogate all inherited variation affecting colon cancer susceptibility genes. Genotypic-phenotypic data are stored in the InSiGHT Colon Cancer Gene Variant Databases [37]. This registry provides a deeper understanding into both rare and common forms of hereditary CRC syndromes [38]. Recently, InSiGHT formed an international panel of researchers and clinicians to review MMR gene variants submitted to the 
database in an effort to develop, test and apply a five-tiered scheme to classify 2360 unique constitutional MMR gene variants [39]. Out of the 12,006 variant entries in the InSiGHT database, the final outcome of standardized five-tiered InSiGHT classification of constitutional MMR gene variants included 2641 variants as Class 5 (pathogenic), 239 as Class 4 (probably pathogenic), 6982 as Class 3 (unknown), 53 as Class 2 (probably no pathogenicity) and 2091 variants as Class 1 (no known pathogenicity). This is the first large-scale comprehensive classification effort undertaken for the curation of a locus-specific database (LSDB) and providing summary information to assign variant pathogenicity. The InSiGHT initiative has provided a key model of LSDB-centric multidisciplinary collaboration for transparent interpretation of DNA variants. The criteria developed provide the basis for standardizing clinical classification of variants that will aid to inform patient and family management through genetic counseling [37,39].

\section{Screening for Lynch Syndrome}

Hereditary colorectal cancer syndromes encompass a spectrum of diseases that are caused by an equally diverse number of germline mutations. Although Lynch syndrome accounts for up to $5 \%$ of CRCs, affected individuals carry up to $80 \%$ lifetime risk for developing CRC and other cancers at an average age of 46 years [1,2]. This has significant public health implications especially in regards to patient selection for timely screening.

Several guidelines pertaining to familial CRC surveillance and screening have been proposed by a number of bodies [40-43], the largest of which being the National Comprehensive Cancer Network guidelines (NCCN) [43]. Germline MMR gene mutations are only detected in up to $80 \%$ of Lynch syndrome instances despite meeting the Amsterdam criteria and showing high MSI/loss of MMR protein expression [44-47]. The syndrome is now an amalgam of a number of molecular entities and even with the introduction of the revised Bethesda guidelines, up to $28 \%$ of MMR gene mutation carriers are missed $[15,48]$. The Amsterdam and Bethesda guidelines have been criticized for lacking in specificity and sensitivity thereby making them difficult to implement in clinical practice [34]. Other studies have also shown that the Bethesda guidelines may miss 6\%-25\% of mutation carriers $[49,50]$. Therefore, clinicians should make a major effort to document detailed family histories in order to identify families with Lynch syndrome.

Much debate exists regarding testing for MSI status by PCR only or MMR protein expression by IHC as there is a strong concordance between the two. Immunohistochemical staining provides a rapid, cost effective way for assessing the protein expression of the MLH1, MSH2, MSH6, and PMS2 genes. Should one or more of these MMR proteins not stain, germline genetic testing can then be targeted to that particular gene [51,52]. To assess Lynch syndrome tumor screening programs and identify barriers to implementation, an electronic survey of the National Society of Genetic Counselors Cancer Special Interest Group was conducted in July 2011 [44]. Routine Lynch syndrome tumor screening protocols for newly diagnosed colon and/or endometrial cancers were set in place according to $52.8 \%$ of respondents and approximately half of these utilized a universal approach. Much variation existed regarding tumor screening methods; $64.2 \%$ started with immunohistochemistry, $20.8 \%$ started with MSI testing and $15.1 \%$ performed both on newly diagnosed CRC. Only $21.7 \%$ of respondents had a tumor-screening program in place for newly diagnosed endometrial cancers. Written consent was 
rarely obtained (7.1\%) and there was a lack of uniformity in the way patients received their results. Several barriers to implementation were concerns regarding cost, bringing key players together and convincing medical staff of the necessity [44].

Overall, Lynch syndrome tumor screening programs are available however protocols vary widely. The current algorithm of making the diagnosis of Lynch syndrome involves meeting the criteria laid out in the Bethesda guidelines. If such criteria are not met, some authors feel there is little to no advantage in performing further genetic tests [22]. Conversely others advocate the routine screening of CRC pathology specimens for MSI and immunohistochemical expression of MMR [53,54]. This approach has been shown to have a better rate of identifying mutation carriers as compared to relying solely on the Bethesda guidelines. The Evaluation of Genomic Applications in Practice and Prevention (EGAPP) Working Group have advocated Lynch syndrome screening on all newly diagnosed CRC patients for the benefit of identifying at-risk relatives [17]. Recently, the revised guidelines for the clinical management of Lynch syndrome recommended that all CRC ( $<70$ years) and all endometrial cancers ( $<70$ years) should be tested by immunohistochemistry or MSI for the identification of patients potentially with Lynch syndrome [34]. These recommendations have been incorporated in the updated NCCN guidelines for Genetic/Familial-Risk Assessment: Colorectal Version I.2014 [43].

\section{Conclusions}

Despite the imperfections of current genetic testing, clinical judgment should dictate management plans and at risk patients should be enrolled in regular CRC surveillance programs. Patients who have a confirmed MMR gene mutation should undergo colonoscopy every 1-2 years beginning at the age of 20-25, or 10 years before the earliest age of onset in the family [44]. There has been a steady increase in Lynch syndrome tumor screening programs since 2000 and institutions are rapidly adopting a universal screening approach. It is time to standardize institutional high-risk/hereditary CRC clinics. International guidelines should determine the requirements and quality standards for establishing these clinics.

\section{Author Contributions}

All authors contributed equally.

\section{Conflicts of Interest}

The authors declare no conflict of interest.

\section{References}

1. Hampel, H.; Frankel, W.L.; Martin, E.; Arnold, M.; Khanduja, K.; Kuebler, P.; Clendenning, M.; Sotamaa, K.; Prior, T.; Westman, J.A.; et al. Feasibility of screening for Lynch syndrome among patients with colorectal cancer. J. Clin. Oncol. 2008, 26, 5783-5788.

2. De Jong, A.E.; Morreau, H.; van Puijenbroek, M.; Eilers, P.H.; Wijnen, J.; Nagengast, F.M.; Griffioen, G.; Cats, A.; Menko, F.H.; Kleibeuker, J.H. The role of mismatch repair gene defects in the development of adenomas in patients with HNPCC. Gastroenterology 2004, 126, 42-48. 
3. Warthin, A.S. Heredity with reference to carcinoma as shown by the study of the cases examined in the pathological laboratory of the University of Michigan, 1895-1913. Arch. Intern. Med. 1913, 12, 546-555.

4. Thorson, A.G.; Knezetic, J.A.; Lynch, H.T. A century of progress in hereditary nonpolyposis colorectal cancer (Lynch syndrome). Dis. Colon Rectum 1999, 42, 1-9.

5. Boland, C.R.; Lynch, H.T. The History of Lynch Syndrome. Fam. Cancer 2013, 12, 145-157.

6. Lynch, H.T.; Krush A.J.; Cancer family “G” revisited: 1895-1970. Cancer 1971, 27, 1505-1511.

7. Douglas, J.A.; Gruber, S.B.; Meister, K.A.; Bonner, J.; Watson, P.; Krush, A.J.; Lynch, H.T. History and molecular genetics of Lynch syndrome in family G: A century later. JAMA 2005, 294, 2195-2202.

8. Boland, C.R.; Troncale, F.J. Familial colonic cancer without antecedent polyposis. Ann. Intern. Med. 1984, 100, 700-701.

9. Lynch, H.T.; Kimberling, W.; Albano, W.A. Hereditary nonpolyposis colorectal cancer (Lynch syndromes I and II). I. Clinical description of resource. Cancer 1985, 56, 934-938.

10. Lynch, H.T.; Schuelke, G.S.; Kimberling, W.J. Hereditary nonpolyposis colorectal cancer (Lynch syndromes I and II). II. Biomarker studies. Cancer 1985, 56, 939-951.

11. Vasen, H.F.; Mecklin, J.P.; Khan, P.M.; Lynch, H.T. The International Collaborative Group on Hereditary Non-Polyposis Colorectal Cancer (ICG-HNPCC). Dis. Colon Rectum 1991, 34, 424-425.

12. Vasen, H.F.; Watson, P.; Mecklin, J.P.; Lynch, H.T. New clinical criteria for hereditary nonpolyposis colorectal cancer (HNPCC, Lynch syndrome) proposed by the International Collaborative group on HNPCC. Gastroenterology 1999, 116, 1453-1456.

13. Rodriguez-Bigas, M.A.; Boland, C.R.; Hamilton, S.R.; Henson, D.E.; Jass, J.R.; Khan, P.M.; Lynch, H.; Perucho, M.; Smyrk, T.; Sobin, L.; et al. A National Cancer Institute Workshop on Hereditary Nonpolyposis Colorectal Cancer Syndrome: Meeting highlights and Bethesda guidelines. J. Natl. Cancer Inst. 1997, 89, 1758-1762.

14. Boland, C.R.; Thibodeau, S.N.; Hamilton, S.R.; Sidransky, D.; Eshleman, J.R.; Burt, R.W.; Meltzer, S.J.; Rodriguez-Bigas, M.A.; Fodde, R.; Ranzani, G.N.; et al. A National Cancer Institute Workshop on Microsatellite Instability for cancer detection and familial predisposition: Development of international criteria for the determination of microsatellite instability in colorectal cancer. Cancer Res. 1998, 58, 5248-5257.

15. Umar, A.; Boland, C.R.; Terdiman, J.P.; Syngal, S.; de la Chapelle, A.; Rüschoff, J.; Fishel, R.; Lindor, N.M.; Burgart, L.J.; Hamelin, R.; et al. Revised Bethesda Guidelines for hereditary nonpolyposis colorectal cancer (Lynch syndrome) and microsatellite instability. J. Natl. Cancer Inst. 2004, 96, 261-268.

16. Boland, C.R.; Shike, M. Report from the Jerusalem workshop on Lynch syndrome-hereditary nonpolyposis colorectal cancer. Gastroenterology 2010, 138, 2197.e1-2197.e17.

17. Evaluation of Genomic Applications in Practice and Prevention (EGAPP) Working Group. Recommendations from the EGAPP Working Group: Genetic testing strategies in newly diagnosed individuals with colorectal cancer aimed at reducing morbidity and mortality from Lynch syndrome in relatives. Genet. Med. 2009, 11, 35-41. 
18. Aaltonen, L.A.; Peltomaki, P.; Leach, F.S.; Sistonen, P.; Pylkkänen, L.; Mecklin, J.P.; Järvinen, H.; Powell, S.M.; Jen, J.; Hamilton, S.R.; et al. Clues to the pathogenesis of familial colorectal cancer. Science 1993, 260, 812-816.

19. Thibodeau, S.N.; Bren, G.; Schaid, D. Microsatellite instability in cancer of the proximal colon. Science 1993, 260, 816-819.

20. Ionov, Y.; Peinado, M.A.; Malkhosyan, S.; Shibata, D.; Perucho, M. Ubiquitous somatic mutations in simple repeated sequences reveal a new mechanism for colonic carcinogenesis. Nature 1993, 363, 558-561.

21. Fishel, R.; Kolodner, R.D. Identification of mismatch repair genes and their role in the development of cancer. Curr. Opin. Genet. Dev. 1995, 5, 382-395.

22. Lynch, H.T.; Boland, C.R.; Rodriguez-Bigas, M.A.; Amos, C.; Lynch, J.F.; Lynch, P.M. Who should be sent for genetic testing in hereditary colorectal cancer syndromes? J. Clin. Oncol. 2007, $25,3534-3542$.

23. Jass, J.R. Classification of colorectal cancer based on correlation of clinical, morphological and molecular features. Histopathology 2007, 50, 113-130.

24. Laurent-Puig, P.; Cayre, A.; Manceau, G.; Buc, E.; Bachet, J.B.; Lecomte, T.; Rougier, P.; Lievre, A.; Landi, B.; Boige, V. Analysis of PTEN, BRAF, and EGFRstatus in determining benefit from cetuximab therapy in wild-type KRAS metastatic colon cancer. J. Clin. Oncol. 2009, 27, 5924-5930.

25. Barnetson, R.A.; Tenesa, A.; Farrington, S.M.; Nicholl, I.D.; Cetnarskyj, R.; Porteous, M.E.; Campbell, H.; Dunlop, M.G. Identification and survival of carriers of mutations in DNA mismatch-repair genes in colon cancer. N. Engl. J. Med. 2006, 354, 2751-2763.

26. Hampel, H.; Frankel, W.L.; Martin, E.; Arnold, M.; Khanduja, K.; Kuebler, P.; Nakagawa, H.; Sotamaa, K.; Prior, T.W.; Westman, J.; et al. Screening for the Lynch syndrome (hereditary nonpolyposis colorectal cancer). N. Engl. J. Med. 2005, 352, 1851-1860.

27. Vasen, H.F.; Stormorken, A.; Menko, F.H.; Nagengast, F.M.; Kleibeuker, J.H.; Griffioen, G.; Taal, B.G.; Moller, P.; Wijnen, J.T. MSH2 mutation carriers are at higher risk of cancer than MLH1 mutation carriers: A study of hereditary nonpolyposis colorectal cancer families. J. Clin. Oncol. 2001, 19, 4074-4080.

28. Lin, K.M.; Shashidharan, M.; Ternent, C.A.; Thorson, A.G.; Blatchford, G.J.; Christensen, M.A.; Lanspa, S.J.; Lemon, S.J.; Watson, P.; Lynch, H.T.; et al. Colorectal and extracolonic cancer variations in MLH1/MSH2 hereditary nonpolyposis colorectal cancer kindreds and the general population. Dis. Colon Rectum 1998, 41, 428-433.

29. Hendriks, Y.M.; Wagner. A.; Morreau. H.; Menko, F.; Stormorken, A.; Quehenberger, F.; Sandkuijl, L.; Møller, P.; Genuardi, M.; van Houwelingen, H. Cancer risk in hereditary nonpolyposis colorectal cancer due to MSH6 mutations: Impact on counseling and surveillance. Gastroenterology 2004, 127, 17-25.

30. Buchanan, D.D.; Tan, Y.Y.; Walsh, M.D.; Clendenning, M.; Metcalf, A.M.; Ferguson, K.; Arnold, S.T.; Thompson, B.A.; Lose, F.A.; Parsons, M.T.; et al. Tumor Mismatch Repair Immunohistochemistry and DNA MLH1 Methylation Testing of Patients With Endometrial Cancer Diagnosed at Age Younger Than 60 Years Optimizes Triage for Population-Level Germline Mismatch Repair Gene Mutation Testing. J. Clin. Oncol. 2014, 32, 90-100. 
31. Senter, L.; Clendenning, M.; Sotamaa, K.; Hampel, H.; Green, J.; Potter, J.D.; Lindblom, A.; Lagerstedt, K.; Thibodeau, S.N.; Lindor, N.M.; et al. The clinical phenotype of Lynch syndrome due to germ-line PMS2 mutations. Gastroenterology 2008, 135, 419-428.

32. Ligtenberg, M.J.; Kuiper, R.P.; Chan, T.L.; Goossens, M.; Hebeda, K.M.; Voorendt, M.; Lee, T.Y.; Bodmer, D.; Hoenselaar, E.; Hendriks-Cornelissen, S.J.; et al. Heritable somatic methylation and inactivation of MSH2 in families with Lynch syndrome due to deletion of the 3' exons of TACSTD1. Nat. Genet. 2009, 41, 112-117.

33. Kempers, M.J.; Kuiper, R.P.; Ockeloen, C.W.; Chappuis, P.O.; Hutter, P.; Rahner, N.; Schackert, H.K.; Steinke, V.; Holinski-Feder, E.; Morak, M.; et al. Risk of colorectal and endometrial cancers in EPCAM deletion-positive Lynch syndrome: A cohort study. Lancet Oncol. 2011, 12, 49-55.

34. Vasen, H.F.; Blanco, I.; Aktan-Collan, K.; Gopie, J.P.; Alonso, A.; Aretz, S.; Bernstein, I.; Bertario, L.; Burn, J.; Capella, G.; et al. Revised guidelines for the clinical management of Lynch syndrome (HNPCC): Recommendations by a group of European experts. Gut 2013, 62, 812-823.

35. Wijnen, J.T.; Brohet, R.M.; van Eijk, R.; Jagmohan-Changur, S.; Middeldorp, A.; Tops, C.M.; van Puijenbroek, M.; Ausems, M.G.; Gómez García, E.; Hes, F.J.; et al. Chromosome 8q23.3 and 11q23.1 variants modify colorectal cancer risk in Lynch syndrome. Gastroenterology 2009, 136, $131-137$.

36. Lindor, N.M.; Rabe, K.; Petersen, G.M.; Haile, R.; Casey, G.; Baron, J.; Gallinger, S.; Bapat, B.; Aronson, M.; Hopper, J.; et al. Lower cancer incidence in Amsterdam-I criteria families without mismatch repair deficiency: Familial colorectal cancer type X. JAMA 2005, 293, 1979-1985.

37. InSiGHT: Colon Cancer Gene Variant Databases. Available online: http://chromium.liacs.nl/ LOVD2/colon_cancer/home.php/ (accessed on 5 February 2014).

38. Kohonen-Corish, M.R.; Macrae, F.; Genuardi, M.; Aretz, S.; Bapat, B.; Bernstein, I.T.; Burn, J.; Cotton, R.G.; den Dunnen, J.T.; Frebourg, T.; et al. Deciphering the colon cancer genes-Report of the InSiGHT-Human Variome Project Workshop, UNESCO, Paris, 2010. Hum. Mutat. 2011, 32, 491-494.

39. Thompson, B.A.; Spurdle, A.B.; Plazzer, J.P.; Greenblatt, M.S.; Akagi, K.; Al-Mulla, F.; Bapat, B.; Bernstein, I.; Capellá, G.; den Dunnen, J.T.; et al. Application of a 5 tiered scheme for standardized classification of 2360 unique mismatch repair gene variants in the InSiGHT locus specific database. Nat. Genet. 2014, 46, 107-115.

40. Smith, R.A.; von Eschenbach, A.C.; Wender, R.; Levin, B.; Byers, T.; Rothenberger, D.; Brooks, D.; Creasman, W.; Cohen, C.; Runowicz, C.; et al. American Cancer Society guidelines for the early detection of cancer: Update of early detection guidelines for prostate, colorectal, and endometrial cancers. CA Cancer J. Clin. 2001, 51, 38-75.

41. Winawer, S.; Fletcher, R.; Rex, D.; Bond, J.; Burt, R.; Ferrucci, J.; Ganiats, T.; Levin, T.; Woolf, S.; Johnson, D.; et al. Colorectal cancer screening and surveillance: Clinical guidelines and rationale update based on new evidence. Gastroenterology 2003, 124, 544-560. 
42. Church, J.; Simmang, C.; Standards Task Force; American Society of Colon and Rectal Surgeons; Collaborative Group of the Americas on Inherited Colorectal Cancer and the Standards Committee of The American Society of Colon and Rectal Surgeons. Practice parameters for the treatment of patients with dominantly inherited colorectal cancer (familial adenomatous polyposis and hereditary nonpolyposis colorectal cancer). Dis. Colon Rectum 2003, 46, 1001-1012.

43. National Comprehensive Cancer Network: NCCN Practice Guidelines in Oncology. Available online: http://www.nccn.org/professionals/physician_gls/default.asp/ (accessed on 26 January 2014).

44. Cohen, S.A. Current Lynch Syndrome Tumor Screening Practices: A Survey of Genetic Counselors. J. Genet. Couns. 2014, 23, 38-47.

45. Patel, S.G.; Ahnen, D.J. Familial colon cancer syndromes: An update of a rapidly evolving field. Curr. Gastroenterol. Rep. 2012, 14, 428-438.

46. Polakis, P. The many ways of Wnt in cancer. Curr. Opin. Genet. Dev. 2007, 17, 45-51.

47. De la Chapelle, A.; Palomaki, G.; Hampel, H. Identifying Lynch syndrome. Int. J. Cancer 2009, 125, 1492-1493.

48. Kastrinos, F.; Balmaña, J.; Syngal, S. Prediction models in Lynch syndrome. Fam. Cancer. 2013 12, 217-228.

49. Tranø, G.; Wasmuth, H.H.; Sjursen, W.; Hofsli, E.; Vatten, L.J. Awareness of heredity in colorectal cancer patients is insufficient among clinicians: A Norwegian population-based study. Colorectal Dis. 2009, 11, 456-461.

50. Mvundura, M.; Grosse, S.D.; Hampel, H.; Palomaki, G.E. The cost-effectiveness of genetic testing strategies for Lynch syndrome among newly diagnosed patients with colorectal cancer. Genet. Med. 2010, 12, 93-104.

51. Aoki, K.; Taketo, M.M. Adenomatous polyposis coli (APC): A multi-functional tumor suppressor gene. J. Cell. Sci. 2007, 120, 3327-3335.

52. Hampel, H. Point: Justification for Lynch syndrome screening among all patients with newly diagnosed colorectal cancer. J. Natl. Compr. Cancer Netw. 2010, 8, 597-601.

53. Sanchez, J.A.; Vogel, J.D.; Kalady, M.F.; Bronner, M.P.; Skacel, M.; Church, J.M. Identifying Lynch syndrome: We are all responsible. Dis. Colon Rectum 2008, 51, 1750-1756.

54. Moreira, L.; Balaguer, F.; Lindor, N.; de la Chapelle, A.; Hampel, H.; Aaltonen, L.A.; Hopper, J.L.; Le Marchand, L.; Gallinger, S.; Newcomb, P.A.; et al. Identification of Lynch syndrome among patients with colorectal cancer. JAMA 2012, 308, 1555-1565.

(C) 2014 by the authors; licensee MDPI, Basel, Switzerland. This article is an open access article distributed under the terms and conditions of the Creative Commons Attribution license (http://creativecommons.org/licenses/by/3.0/). 